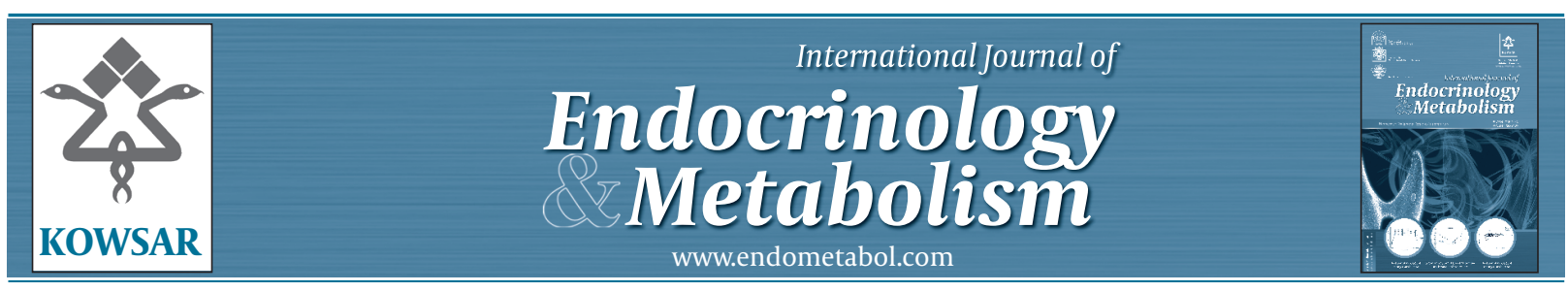

\title{
Non-Contraceptive Benefits of Oral Hormonal Contraceptives
}

\author{
Adolf E Schindler ${ }^{1^{*}}$ \\ ${ }^{1}$ Institute for Medical Research and Education, Essen, Germany \\ * Corresponding author: Adolf E Schindler, Institute for Medical Research and Education, University Clinic, Hufelandstrasse 55, D-45147, Essen, Germany. Tel.: \\ +49-2017991833, Fax: +49-2017499533, E-mail: adolf.schindler@uni-due.de
}

\begin{abstract}
A B S T R A C T
Abstract: It is becoming evident that oral hormonal contraceptives besides being well established contraceptives - seem to become important medications for many functional or organic disturbances. So far, clinical effectiveness has been shown for treatment as well as prevention of menstrual bleeding disorders and menstrual-related pain symptoms. Also this is true for premenstrual syndrome (PMS) and premenstrual disphoric disorder (PMDD).
\end{abstract}

Keywords: Contraceptives; Oral; Hormonal; Therapeutics; Prevention and Control

Copyright @ (2013,Research Institute For Endocrine Sciences and Iran Endocrine Society; Published by Kowsar Corp.

\section{Introduction}

Since starting intake of oral hormonal contraceptives as combined estrogen/ progestogen formulation in 1960, these drugs have experienced a steady change in utilized progestogens having different patterns of partial effects in addition to its basic effects. These aspects of progestogen actions have proven to be useful in incorporating by and by non-contraceptive use of these hormonal contraceptives into the list of indications creating a wide range of beneficial effects besides the primary aims. Also, some changes have been implemented in estrogen component. Although OCs started with mestranol and ethinylestradiol, intake of mestranol was abandoned because of its conversion to ethinylestradiol in the body. After about
50 years, recently hormonal contraceptives are further developed by either estradiol valerate or micronized estradiol as estrogen component associated with lowering effect on thromboembolic risk.

Awareness to non-contraceptive benefits of hormonal contraceptives has to be enforced because these hormonal contraceptives besides their undoubtedly high contraceptive efficacy have been shown to be also highly effective in their non-contraceptive benefits. In addition to high therapeutic value in different medical indications, there are very favorable cost/benefit ratio and high level of toleration for these drugs compared to other indicated medications.

Therefore, this paper was aimed to gather and classify

Article type: Review Article; Received: 15 Jan 2012, Revised: 12 May 2012, Accepted: 23 Jun 2012; DOI: 10.5812/ijem.4158

-Implication for health policy/practice/research/medical education:

Demonstration of the clinical usefulness of various hormonal contraceptives to treat with favourable cost-effectiveness a number of clinical conditions in women.

-Please cite this paper as:

Schindler AE. Non-Contraceptive Benefits of Oral Hormonal Contraceptives. Int J Endocrinol Metab. 2013;11(1):41-7. DOI:10.5812| ijem.4158

Copyright (C) 2013,Research Institute For Endocrine Sciences and Iran Endocrine Society; Published by Kowsar Corp.

This is an Open Access article distributed under the terms of the Creative Commons Attribution License (http://creativecommons.org/licenses/by/3.0), which permits unrestricted use, distribution, and reproduction in any medium, provided the original work is properly cited. 
different clinical entities associated with cyclic use of oral hormonal contraceptives for effective treatment of various clinical conditions ( Table 1 ). Recently, it was stated that non-contraceptive health benefits were recognized as an important aspect of overall impacts of oral hormonal contraceptives (1).

Table 1. Clinical Entities in Which Treatment, Prevention, and Risk Reduction by Hormonal Contraceptives Have Been Shown.

\begin{tabular}{l}
\hline Disorders \\
\hline 1-Menstrual bleeding disorders \\
Bleeding interval and regularity (poly- and oligomenorrhea) \\
Amount of bleeding (hypermenorrhea/menorrhagia) \\
2-Dysmenorrhea \\
\hline 3-Signs of androgenisation (seborrhea, acne, hirsutism, alopecia) \\
\hline 4-Premenstrual syndrome (PMS) / Premenstrual dysphoric disorder (PMDD) \\
\hline 5-Ovarian cysts \\
\hline 6-Endometriosis/adenomyosis \\
\hline 7-Myoma \\
\hline 8-Pelvic inflammatory disease (PID) \\
9-Rheumatoid arthritis \\
10-Multiple sclerosis \\
\hline 11-Menstrual migraine \\
12-Bone structure \\
\hline 13-Voice \\
\hline
\end{tabular}

\section{4-Asthma}

15-Benign breast disease

16-Ovarian cancer

17-Endometrial hyperplasia/Endometrial cancer

18-Colon cancer

Hypertension defined as current use of antihypertensive drugs or BP more than 140/90 mmHg on two separate occasions Hyperlipidemia: Fasting TG $>150 \mathrm{mg}$ per deciliter TC $>240$ and or LDL $>160 \mathrm{mg}$ per deciliter

\section{Menstrual Bleeding Disorders}

Excluding malignancies, menstrual bleeding disorders are common- diseases that can lead to pain, anemia, and loss of quality of life. Indeed, primary oral hormonal contraceptives were approved by the Food and Drug Administration (FDA) for treatment of menstrual disorders (2). None of these therapeutic uses appear in the FDA-approved labeling for currently marketed OCs (3).

Combined estrogen/progestogen preparations are preferentially monophasic drugs of choice for cyclic intakes. Also, extended regimens or constant management are progressively apply applied (4). This improves, on the one hand, the effectiveness and on the other hand, the attractive convenience of such regimens $(5,6)$.

\section{Dysmenorrhea}

Menstruation associated dysmenorrhea is a relatively frequent event, which can force women to even withdraw from school or work and cause considerable impacts on quality of life. Dysmenorrhea is considered to be the main symptom in women with, but not limited to, endometriosis. Today, dysmenorrheal hormonal contraceptive pills as monophasic estrogen/progestogen combinations are considered as the first choice to subside pain symptoms. In case of insufficient effect, "long-cycle regimen" or constant usage is recommended. The optimal individual effect can be achieved when amenorrhea occurs during which quality of life improves to its best (7).

\section{Symptoms of Androgenisation (Seborrhea, Acne, Hirsutism, Alopecia)}

In general, combined estrogen/progestogen preparations have been useful to treat symptoms of androgenisation because androgens secreted from the ovary will be suppressed and sex hormone binding globulin elevated that in turn will decrease the amount of free, biologically active androgens which reduce the negative action of androgens on sebaceous glands and hair follicles $(7,8)$. In addition, there are four progestogens, i.e. cyproterone acetate, dienogest, drospirenone, and chlormadinone 
acetate, with distinct anti-androgenic action by blocking androgen receptors and inhibiting action of circulating androgens. The progestogen with the highest anti-androgenic activity is cyproterone acetate (8). Besides treating effectively the symptoms of androgenisation, there was normalization of the ovaries in structure and size in women with polycystic ovary syndrome (PCOS). The volume of the ovaries as well as the number of follicles decreased. All these effects were highly significant $(9,10)$. Also, these favorable structural changes continued to be present to some extent after the pill cessation. In addition, it was demonstrated that in some of those women, pattern and function of menstrual cycle improved after the treatment ( Table 2 and Table 3$)(10,11)$.

Table 2. Changes of Ovarian Volume and Number of Ovarian Follicles Before and After Treatment With 0,35 mg Ethinylestradiol And $2 \mathrm{Mg}$ Cyproterone Acetate According to 9.

\begin{tabular}{|lllll}
\hline Time & $\begin{array}{l}\text { Right } \\
\text { Ovary, } \\
\text { cm }^{3}\end{array}$ & $\begin{array}{l}\text { Number } \\
\text { of Cystic } \\
\text { Follicles }\end{array}$ & $\begin{array}{l}\text { Left } \\
\text { Ovary, } \\
\text { cm }^{3}\end{array}$ & $\begin{array}{l}\text { Number } \\
\text { of Cystic } \\
\text { Follicles }\end{array}$ \\
\hline $\begin{array}{l}\text { Before } \\
\text { therapy }\end{array}$ & 17.3 & 6.8 & 18.5 & 6.3 \\
\hline $\begin{array}{l}\text { During } \\
\text { therapy }\end{array}$ & 8.3 & 1.2 & 7.6 & 1.1 \\
\hline $\begin{array}{l}\text { After } \\
\text { therapy }\end{array}$ & 13.2 & 5.1 & 10.7 & 4.1 \\
\hline
\end{tabular}

Table 3. Changes of Ovarian Volume, Number of Cystic Follicles, and Percentage of Women with PCOS Treated for 6 Cycles With 0,035 mg Ethinylestradiol and $2 \mathrm{mg}$ Cyproterone Acetate with Post Therapy Follow-Up of 6 Month According to 10.

\begin{tabular}{|c|c|c|c|}
\hline Parameter & Baseline & $\begin{array}{l}60 \text { Treat- } \\
\text { ment Cycles }\end{array}$ & $\begin{array}{l}6 \text { Month } \\
\text { After }\end{array}$ \\
\hline $\begin{array}{l}\text { Ovarian vol- } \\
\text { ume, } \mathrm{cm} 3\end{array}$ & $15.1 \pm 2.9$ & $6.3 \pm 1.1^{\mathrm{a}}$ & $9.5 \pm 2.1^{b, c}$ \\
\hline $\begin{array}{l}\text { Number of } \\
\text { cystic fol- } \\
\text { licles }\end{array}$ & $12.1 \pm 1.9$ & $1.3 \pm 0.7^{\mathrm{a}}$ & $8.2 \pm 1.8^{b, c}$ \\
\hline Stroma,\% & 20 & 50 & 35 \\
\hline
\end{tabular}

\section{Premenstrual Syndrome (PMS) and Premenstrual Disphoric Disorder (PMDD)}

Both PMS and PMDD disappear during pregnancy and lactation, or after the failure of hypothalamic-pituitaryovarian axis, or after natural or surgical menopause (12). Some effects were observed primarily by hormonal contraceptives. The introduction of hormonal contraceptives containing drospirenone with a strong antimineralocorticoid effect resulted in an effective clinical treatment regimen; the efficiency was increased by an extended regimen of switching from Yasmin $®(21 / 7)$ to Yaz® $(24 / 4)(7,12,13)$. The latter preparation was recognized by FDA as a treatment modality for PMDD.

\section{Ovarian Cysts}

There is a protection for both follicular and corpus luteum cysts if hormonal contraceptives suppress hypothalamic-pituitary-ovarian axis, properly that depends, for instance, on the type of hormonal contraceptives used as shown in Table 4. This can contribute to avoid the operation (14).

Table 4. Changes in Menstrual Cycle Function After 2 Years of Treatment with 0,035 mg Ethinylestradiol and 2 mg Cyproterone Acetate According to 9.

\begin{tabular}{|c|c|}
\hline \multicolumn{2}{|c|}{ Menstrual Cycle Function } \\
\hline Prior to therapy & Patients No. (\%) \\
\hline Anovulation & $28(84.9)$ \\
\hline Oligoovulation & $5(15.1)$ \\
\hline \multicolumn{2}{|l|}{ After therapy } \\
\hline Ovulation & $15(45.4)$ \\
\hline \multicolumn{2}{|c|}{ Menstrual Cycle Length } \\
\hline Prior to therapy & Patients No. (\%) \\
\hline Amenorrhea & $4(12.1)$ \\
\hline Oligomenorrhea & $22(66.6)$ \\
\hline Eumenorrhea & $7(21.2)$ \\
\hline \multicolumn{2}{|l|}{ After therapy } \\
\hline Eumenorrhea & $14(42.4)$ \\
\hline
\end{tabular}

\section{Endometriosis/Adenomyosis}

Combined estrogen/progestogen pills with a dominant action of progestogen effectively influence on endometriosis-related pain symptoms (15). This treatment can fail for which a so-called long-cycle regimen was introduced (16). However, today, one may start a constant, progestogen-dominant, monophasic combined estrogen/progestogen preparations, instantly. Indeed, the Royal College of Obstetrician Gynecologists recommends combined estrogen/progestogen pill as drug of choice for treating symptoms of endometriosis. This is considered as a safe and economical treatment and as an alternative to surgery (17). This type of therapy not only alleviates pain symptoms but also reduces the size of endometriosis lesions. This effect can be best accomplished by constant regimens over long periods of time (18-20). The approach has been found suitable for women surgically treated for endometrioma in order to avoid recurrence and subsequent surgery, and to preserve ovarian function and capacity. Similar to endometriosis, the adenomyosis- 
related symptoms (dysmenorrhea, heavy bleeding and enlarged as well as painful uterus) can be favorably influenced by oral hormonal contraceptives (21).

\section{Myoma}

Risk of myoma development was significantly reduced among post-treatment and Constant users of combined estrogen/progestogen preparations and the risk decreases with longer management (22). Constant users showed a 70\% reduction of myoma size, and post-treatment users, who used the pills for seven and more years, demonstrated a $50 \%$ reduction of myoma size (23).

\section{Pelvic Inflammatory Disease (PID)}

It has been found that oral hormonal contraceptives reduce the risk of PID by $50 \%$ to $60 \%$ (24). This leads to a reduction inhospitalization days, amount of medication and operative procedures, and also the risk of ectopic pregnancy and infertility problems (3). Besides the risk reduction between 50-70\%, PID occurring during the pill intake seems to be associated with less severe inflammation as judged by laparoscopy (12).

\section{Rheumatoid Arthritis}

Oral contraceptives are found to decrease the risk of rheumatoid arthritis by about $30 \%$ and in hospital-based case studies by $51 \%$ (25). In women who used oral hormonal contraceptives for more than five years the relative risk of developing mild disease was RR 0,10; 95\%CI 0,01-0,06 (26). However, it appears that hormonal contraceptives do not significantly influence the long-term outcome of the disease (27).

\section{Multiple Sclerosis}

Recently it was reported that the age of first MS-symptoms was significantly higher among women who had oral hormonal contraceptives compared to women who did not (onset at 31 years versus 33 years). The age for onset of MS increased in proportion to the increased duration of OC intake, from 24 years with less than 1 year of OC intake to 31 years with more than 10 years OC intake. The women's age at primary symptoms is significantly higher among women who gave birth before the onset of MS compared to those who did not (onset at 31 years versus 33 years) (28).

\section{Menstrual Migraine}

The basic principle in women with menstrual migraine without aura is just minimal changes in hormonal concentrations or elimination of hormonal changes all together. This can be accomplished by eliminating the standard 7day free interval of oral hormonal contraceptive pills and taking a ‘long-cycle` or constant regimen $(29,30)$.

\section{Bone Structure}

Preservation of bone mineral density will occur with oral hormonal contraceptives when a hypoestrogenic state is present, particularly in younger aged women, or ovarian function declines in older premenopausal women . With long-term use of oral hormonal contraceptives ( $>5$ years) protection increases in proportion to the increased duration of the use (31).

\section{Voice}

Vocal cords are hormone-dependent structures and therefore influenced by pathological changes of circulating hormone parameters such as androgens in the climacterium. In androgen excess, oral hormonal contraceptives with a combination of ethinylestradiol and a progestogen having anti-androgenic properties can lead to voice improvement or resumption. Similar positive clinical effects can be experienced in climacteric women when lack of estradiol and dominance of androgen effects may become relevant. Also, in this situation a combination of estradiol/estradiol valerate and an anti-androgenic progestogen may improve or restore the voice in professional and non-professional singers (32).

\section{Asthma}

Recent studies have indicated that oral hormonal contraceptives help to reduce asthmatic symptoms (33).

\section{Endometrial Hyperplasia}

Endometrial hyperplasia can be either prevented (for instance in women with PCOS) or successfully treated by oral hormonal contraceptives showing a progestogen dominance effect at the tissue side.

\section{Benign Breast Disease}

Many studies have shown a decreased risk of benign breast disease in OC users versus non-users. There is a statistically significant decreased risk of benign breast disease with longer duration of intake before the first full term pregnancy (24). The Royal College of General Practitioner Study has shown in 46000 women that a fixed dose of ethinylestradiol combined with increasing dose of the same progestogen (a 19 nor-testosterone derivative) lead to a decreased risk of fibroadenoma in young women (34). The Oxford Family Planning Association Study observed reduced incidences for:

1. Fibrocystic breast disease (30\%),

2. Fibroadenoma (60\%), and

3. Clinically found breast lumps (40\%)

Diminishing the risk increases with longer duration of the use. Constant users demonstrate the lowest risk. A protection lasting up to one year after OC discontinuation was found (35). By the use of OC there was even a 
lower risk of breast ductual hyperplasia compared to women with no OC intake. Constant use and intake of more than eight years was associated with a lower prevalence of breast ductual hyperplasia.

\section{Prevention of Ovarian Cancer}

Risk reduction of ovarian cancer is one of the most important health benefits of oral combined hormonal contraceptives (6). The reduction of ovarian cancer is thought to be the result of suppression of ovulation which on the one hand decreases the injury and subsequent regression of the ovarian surface epithelium and on the other hand there are constant low levels of FSH and LH which also affect the ovarian surface epithelium which is the starting point of most ovarian cancers (12). The beneficial effect is already seen when combined oral hormonal contraceptives are used for as little as three to six months, although an $80 \%$ risk reduction is only achieved after intake for more than 10 years. Using combined oral hormonal contraceptives there is a $6 \%$ decrease of relative risk per year, persisting beyond 15 years of exposure. Intake before pregnancy has additional benefits (36). No difference is seen in risk reduction with different formulations of combined oral hormonal contraceptives including low dose pills $(11,37)$. The risk in four main histological types of epithelial ovarian cancer (serous, endometroid, mucinous, clear cell) are similarly reduced by the use of combined oral hormonal contraceptives, but not in germ cell ovarian malignancies (12). Many larger studies and meta-analyses showed similar results (38-41).

A collaborative reanalysis of worldwide data on combined oral hormonal contraceptives and ovarian cancer involving 45 epidemiologic studies with about 23000 ovarian cancer cases and about 87000 controls has demonstrated that ever use of combined oral hormonal contraceptives decreases the risk of ovarian cancer by $27 \%$. The longer the duration of OC use the greater the risk reduction $(P=0,001)$ leading to a decrease of about $20 \%$ of every five years of use. The risk reduction persisted more than 30 years after combined oral hormonal contraceptives (42). From these data it was calculated that combined oral hormonal contraceptives already prevented around 200000 ovarian cancers and 100000 deaths due to the disease. Over the next decades the number of cancers prevented will rise to at least 30000 cases per year (42).

Recent data also suggest that the combined oral hormonal contraceptives can also provide primary prevention for women at risk for hereditary ovarian cancer. The adjusted odd ratio for ovarian cancer with any use of combined oral hormonal contraceptives compared to never usage was $0.5 ; 95 \%$ CI $0,3-0,8$. The greatest protection was observed with six and more years of intake (OR 0,$3 ; 95 \%$ CI 0,1-0,7) (43). A recent case control study comparing BRCA 1 and BRCA2 mutation cases with controls demonstrated that combined oral hormonal contracep- tives prevented ovarian cancer in these high-risk women (44). Combined oral hormonal contraceptives significantly reduced the risk of ovarian cancer in carriers of BRCA1 (OR 0,56; 95\%CI 0,45-0,71) and BRCA 2 mutations (OR 0,39; 95\% CI 0,23-0,66).

Women with endometriosis represent a high risk group for ovarian cancer. It was found that the use of combined oral hormonal contraceptives for more than 10 years was associated with a substantial reduction in risk among women with endometriosis (OR 0,21; 95\% CI 0,08-0,58) (45).

Therefore, long-term use of combined oral hormonal contraceptives in women with endometriosis may provide substantial protection from ovarian cancer for this high-risk population because of long-term ovulation suppression (45).

\section{Endometrial Cancer}

Women using combined oral hormonal contraceptives show about a 50\% reduction in the risk of endometrial cancer compared to never users, when combined oral hormonal contraceptives are used at least for one year. This protective effect increases with the duration of use and persists more than 20 or more years after discontinuation $(6,12,31,46)$. This result is true for three major histological subtypes of endometrial cancer:1) adenocarcinoma, 2) adenosquamous carcinoma, and 3) adenoacanthoma.

Risk reduction for endometrial cancer was $80 \%$ for high-progestogen-containing pills for more than 10 years since stopping (47) and 70\% for 15 to 19 , and $20 \%$ for 20 and more years since stopping the use of combined oral hormonal contraceptives (39). Similar finding of RR 0,2 for more than 10 years of use was found in Sweden (48).

The subsequent use of hormone replacement therapy did not modify the long-term protecting effect of the previous use of combined oral hormonal contraceptives. Similar results were also obtained in China (48). Lower dose combined oral hormonal contraceptives appear to lead to similar results (31).

\section{Colon Cancer}

Evidence shows that combined oral hormonal contraceptives protect women from developing colon/ rectal cancer (12). Eight case control studies resulted in a pooled RR for colon/rectal cancer of 81\%; 95\% CI 0,69-0,94. The pooled data estimated from cohort studies was RR 0,84; 95\% CI 0,73-0,90; in all studies combined the RR was 0,82; 95\% CI 0,74-0,92.

The reduction was greatest for recent use and showed no duration effect (49). Similar results were obtained by others $(12,38,50-52)$. In a study by the Royal College of General Practitioners the RR for large bowel or rectal cancer was 0,$72 ; 95 \% \mathrm{CI} 0,58-0,90$ for ever use of combined oral hormonal contraceptives (38). A recent large cohort study found a modest reduction in the risk of colon/ rec- 
tal cancer (RR 0,83; 95\% CI 0,73-0,94), but no trend was seen for RR with increased duration of the use of combined oral hormonal contraceptives.

To illustrate oncological non-contraceptive use of combined oral hormonal contraceptives it was recently pointed out that the use of combined oral hormonal contraceptives by nuns would protect them from oncological hazards of nulliparity (53).

\section{Acknowledgements}

None declared.

\section{References}

1. Fraser IS. Non-contraceptive health benefits of intrauterine hormonal systems. Contraception. 2010;82(5):396-403.

2. Asbell B. The pill: a biography of the drug that changed the world. Random House New York. 1995.

3. Kaunitz AM. Oral contraceptive health benefits: perception versus reality. Contraception. 1999;59(1 Suppl):29S-33S.

4. Jensen JT. The befits of reduced menstrual bleeding associated with the use of contraceptive methods. Gynecol Forum. 2010;15:10-4.

5. Fraser IS, Porte RJ, Kouides PA, Lukes AS. A benefit-risk review of systemic haemostatic agents: part 1: in major surgery. Drug Saf. 2008;31(3):217-30.

6. Maia HJ, Casoy J. Non-contraceptive health benefits of oral contraceptives. Eur J Contracept Reprod Health Care. 2008;13(1):17-24

7. Schindler AE. Non-contraceptive use of hormonal contraceptives for women with various medical problems. J Pediat Obstet Gynecol. 2008;34:183-200.

8. Schindler AE. Antiandrogenic progestins for treatment of signs of androgenisation and hormonal contraception. EurJ Obstet Gynecol Reprod Biol. 2004;112:136-41.

9. Falsetti L, Gambera A, Tisi G. Efficacy of the combination ethinyl oestradiol and cyproterone acetate on endocrine, clinical and ultrasonographic profile in polycystic ovarian syndrome. Hum Reprod. 2001;16(1):36-42.

10. Venturoli S, Paradisi R, Saviotti E, Porcu E, Fabbsi R, Orsini LF Ulrtasouns study of ovarian and uterine morphology in women with PCOS before, during and after treatment with CPA and EE. Arch Gynecol.1987;237:1-10.

11. Schindler AE, Mangold K, Friedrich E, Keller E, Göser R. Therapy of androgenetic symptomatology with cyproterone acetate and ethinyl estradiol. Arch Gyn Obst. 1978;225(2):103-7.

12. Huber JC, Bentz EK, Ott J, Tempfer CB. Non-contraceptive benefit of oral contraceptives. Expert Opin Pharmacother. 2008;9(13):2317-25.

13. Sillem M. Yasminelle((R)): a new low-dose combined oral contraceptive containing drospirenone. Womens Health (Lond Engl) 2006;2(4):551-9.

14. Westhoff C, Clark CJ. Benign ovarian cysts in England and Wale and in the United States. Br J Obstet Gynaecol.1992;99(4):329-32.

15. Schindler AE. Pathophysiology, diagnosis and treatment of endometriosis. Minerva Ginecol. 2004;56(5):419-35.

16. Adamson D. Endometriosis: traditional perspectives, current evidence and future possibilities. Int J Fertil Womens Med.2001;46(3):151-68.

17. Haider Z, D'Souza R. Non-contraceptive benefits and risks of contraception. Best Pract Res Clin Obstet Gynaecol. 2009;23(2):249-62.

18. Seracchioli R, Mabrouk M, Manuzzi L, Vicenzi C, Frasca C, Elmakky A, et al. Post-operative use of oral contraceptive pills for prevention of anatomical relapse or symptom-recurrence after conservative surgery for endometriosis. Hum Reprod. 2009;24(11):2729-35.

19. Vercellini P, Pietropaolo G, De Giorgi O, Pasin R, Chiodini A, Crosignani PG. Treatment of symptomatic rectovaginal endometriosis with an estrogen-progestogen combination versus low-dose norethindrone acetate. Fertil Steril. 2005;84(5):1375-87.
20. Vercellini P, Somigliana E, Vigano P, Abbiati A, Barbara G, Crosig nani PG. Endometriosis: current therapies and new pharmacological developments. Drugs. 2009;69(6):649-75.

21. Maia H, Jr., Casoy J, Correia T, Freitas L, Pimentel K, Athayde C. Ef fect of the menstrual cycle and oral contraceptives on aromatase and cyclooxygenase-2 expression in adenomyosis. Gynecol Endocrinol. 2006;22(10):547-51.

22. Ross RK, Pike MC, Vessey MP, Bull D, Yeates D, Casagrande JT. Risk factors for uterine fibroids: reduced risk associated with ora contraceptives. Br Med J (Clin Res Ed). 1986;293(6543):359-62.

23. Chiaffarino F, Parazzini F, La Vecchia C, Marsico S, Surace M, Ricci E. Use of oral contraceptives and uterine fibroids: results from a case-control study. Br J Obstet Gynaecol. 1999;106(8):857-60.

24. Burkman RT. Oral contraceptives: current status. Clin Obstet Gy necol. 2001;44(1):62-72.

25. Spector TD, Hochberg MC. The protective effect of the oral contraceptive pill on rheumatoid arthritis: an overview of the analytic epidemiological studies using meta-analysis. J Clin Epidemiol.1990;43(11):1221-30.

26. Jorgensen C, Picot MC, Bologna C, Sany J. Oral contraception, parity, breast feeding, and severity of rheumatoid arthritis. Ann Rheum Dis. 1996;55(2):94-8.

27. Drossaers-Bakker KW, Zwinderman AH, van Zeben D, Breedveld FC, Hazes JM. Pregnancy and oral contraceptive use do not significantly influence outcome in long term rheumatoid arthritis. Ann Rheum Dis. 2002;61(5):405-8.

28. Holmqvist ST, Hammar M, Lindblom AM, Brynhirdsen J. Age at onset of Multiple sclerosis is correlated to use of combined ora hormonal contraceptives and child birth before diagnosis. Fert Steril. 2010;94:2835-7.

29. Kuhl H, Birkhauser M, Mueck A, Neulen J, Thaler C, Kiesel L, et al. [Long-cycle treatment in oral contraception]. Ther Umsch. 2009;66(2):101-8

30. Sulak P, Willis S, Kuehl T, Coffee A, Clark J. Headaches and oral contraceptives: impact of eliminating the standard 7-day placebo interval. Headache. 2007;47(1):27-37.

31. Williams JK. Noncontraceptive benefits of oral contraceptive use: an evidence-based approach. Int J Fertil Womens Med. 2000;45(3):241-7.

32. La FM, Ledger WL, Davidson JW, Howard DM, Jones GL. The effects of a third generation combined oral contraceptive pill on the classical singing voice. J Voice. 2007;21(6):754-61.

33. Mandhane PJ, Hanna SE, Inman MD, Duncan JM, Greene JM, Wang HY, et al. Changes in exhaled nitric oxide related to estrogen and progesterone during the menstrual cycle. Chest 2009;136(5):1301-7.

34. Royal College of General Practitioners' Oral Contraception Study Effect on hypertension and benign breast disease of progestogen component in combined oral contraceptives.Royal College of General Practitioners' Oral Contraception Study. Effect on hypertension and benign breast disease of progestogen component in combined oral contraceptives. Lancet. 1977;1:624.

35. Brinton LA, Vessey MP, Flavel R, Yeates D. Risk factors for benign breast disease. Am J Epidemiol.1981;113(3):203-14.

36. Siskind V, Green A, Bain C, Purdie D. Beyond ovulation: ora contraceptives and epithelial ovarian cancer. Epidemiology. 2000;11(2):106-10.

37. The reduction in risk of ovarian cancer associated with oralcontraceptive use. The Cancer and Steroid Hormone Study of the Centers for Disease Control and the National Institute of Child Health and Human Development.The reduction in risk of ovarian cancer associated with oral-contraceptive use. The Cancer and Steroid Hormone Study of the Centers for Disease Control and the National Institute of Child Health and Human Development. N Engl J Med.1987;316(11):650-5.

38. Hannaford PC, Selvaraj S, Elliott AM, Angus V, Iversen L, Lee AJ Cancer risk among users of oral contraceptives: cohort data from the Royal College of General Practitioner's oral contraception study. BMJ. 2007;335(7621):651.

39. Lyon: WHO, IARC; 1999.72 p. IARC Monographs on the evaluation of carcinogenic risk to humans. Hormonal contraception and 
postmenopausal hormonal therapy.

40. Tworoger SS, Fairfield KM, Colditz GA, Rosner BA, Hankinson SE. Association of oral contraceptive use, other contraceptive methods, and infertility with ovarian cancer risk. Am J Epidemiol. 2007;166(8):894-901.

41. Vessey M, Painter R. Oral contraceptive use and cancer. Findings in a large cohort study, 1968-2004. Br J Cancer. 2006;95(3):385-9.

42. Beral V, Doll R, Hermon C, Peto R, Reeves G. Collaborative Group on Epidemiological Studies of Ovarian Cancer. Ovarian cancer and oral contraceptives: collaborative reanalysis of data from 45 epidemiological studies including 23,257 women with ovarian cancer and 87,303 controls. Lancet. 2008;371(9609):303-14.

43. Schlesselman JJ. Net effect of oral contraceptive use on the risk of cancer in women in the United States. Obstet Gynecol. 1995;85(5 Pt 1):793-801.

44. McLaughlin JR, Risch HA, Lubinski J, Moller P, Ghadirian P, Lynch $\mathrm{H}$, et al. Reproductive risk factors for ovarian cancer in carriers of BRCA1 or BRCA2 mutations: a case-control study. Lancet Oncol. 2007;8(1):26-34.

45. Modugno F, Ness RB, Allen GO, Schildkraut JM, Davis FG, Goodman MT. Oral contraceptive use, reproductive history, and risk of epithelial ovarian cancer in women with and without endometriosis. Am J Obstet Gynecol. 2004;191(3):733-40.
46. Noncontraceptive health benefits of combined oral contraception.Noncontraceptive health benefits of combined oral contraception. Hum Reprod Update. 2005;11(5):513-25.

47. Weiderpass E, Adami HO, Baron JA, Magnusson C, Lindgren A, Persson I. Use of oral contraceptives and endometrial cancer risk (Sweden). Cancer Causes Control.1999;10(4):277-84.

48. Xu WH, Xiang YB, Ruan ZX, Zheng W, Cheng JR, Dai Q, et al. Menstrual and reproductive factors and endometrial cancer risk: Results from a population-based case-control study in urban Shanghai. Int J Cancer. 2004;108(4):613-9.

49. Fernandez E, La Vecchia C, Balducci A, Chatenoud L, Franceschi S, Negri E. Oral contraceptives and colorectal cancer risk: a metaanalysis. Br J Cancer. 2001;84(5):722-7.

50. Furner SE, Davis FG, Nelson RL, Haenszel W. A case-control study of large bowel cancer and hormone exposure in women. Cancer Res. 1989;49(17):4936-40.

51. Schindler AE. Long-term use of progestogens: colon adenoma and colon carcinoma. Gynecol Endocrinol. 2007;23:42-4

52. Weiss NS, Daling JR, Chow WH. Incidence of cancer of the large bowel in women in relation to reproductive and hormonal factors. J Natl Cancer Inst. 1981;67(1):57-60.

53. Britt K, Short R. The plight of nuns: hazards of nulliparity. Lancet 2012;379(9834):2322-3. 